\title{
Pycnodysostosis: A Case Report of Radiological Analysis.
}

\author{
Dr. Pavani Tummala ${ }^{1}$, Dr. K.Balakoteswara Rao ${ }^{2}$, Dr. B.Seshu Lakshmi ${ }^{3}$ \\ 1. Post graduate resident, Department of Radiodiagnosis, Mamata Medical College, Khammam, AP, INDIA. \\ 2. Professor \& Head of the department of Radiodiagnosis, Mamata Medical College, Khammam, AP, INDIA. \\ 3. Professor, Department of of Radiodiagnosis, Mamata Medical College, Khammam, AP, INDIA.
}

\begin{abstract}
Pycnodysostosis is a rare autosomal recessive disorder that manifests as generalized osteosclerosis of the skeleton as a result of decreased bone turnover. Patients tend to suffer from numerous fractures owing to dense, abnormally brittle bones. This syndrome has a number of characteristic clinical and radiographic signs that differentiate it from other osteosclerotic conditions. Hypoplastic Mandible being the most characteristic diagnostic feature. This is a case report of a family of 3 young males with history of multiple fractures.
\end{abstract}

\section{Introduction:}

Pycnodyostosis is a rare genetic osteosclerotic disorder with an incidence estimated to be 1.7 per million births, first described by Maroteaux and Lamy in $1962^{1,2}$. Other authors have labeled it the ToulouseLautrec syndrome, as the French painter Henri de Toulouse- Lautrec is claimed to have suffered from the disorder $^{2}$. It is an autosomal recessive illness that manifests as a generalised osteosclerosis of the skeleton as a result of decreased bone turnover ${ }^{3}$. Patients present with multiple fractures owing to dense, abnormally brittle bones. Pycnodysostosis has a number of characteristic radiographic signs that differentiate it from other osteosclerotic conditions. Recognition of these radiological signs is important in order to make the diagnosis and prevent possible complications ${ }^{4}$.

\section{Case Report :}

We report a case of 25 year old male with fracture of diaphyseal shaft of tibia following a minor fall 2 weeks prior to presentation. He also provided a history of multiple previous long bone fractures over the course of the previous 8 years, including bilateral femur fractures, bilateral tibia fractures and a right humerus fracture.

On clinical examination, the patient demonstrated dysmorphic features with short stature and proportionately short limbs. He had a large head, with a small facial structure and jaw. Dental examination revealed a narrow palate and teeth with overcrowding. His lower limbs demonstrated angular deformities in keeping with the history of previous fractures. Extremities had short digits with dysplastic nails.

Serum calcium, phosphorous and alakaline phosphatase were found to be normal. The patient was subjected to skeletal survey as he had sclerotic bones on fractured limb.

Skull radiographs showed a large cranial vault with persistent open fontanelles and wide sutures, as well as wormian bones(Fig 1A). The maxilla was hypoplastic with non-pneumatisation of the frontal sinuses. The mandible was underdeveloped with an obtuse jaw angle(Fig 1B).
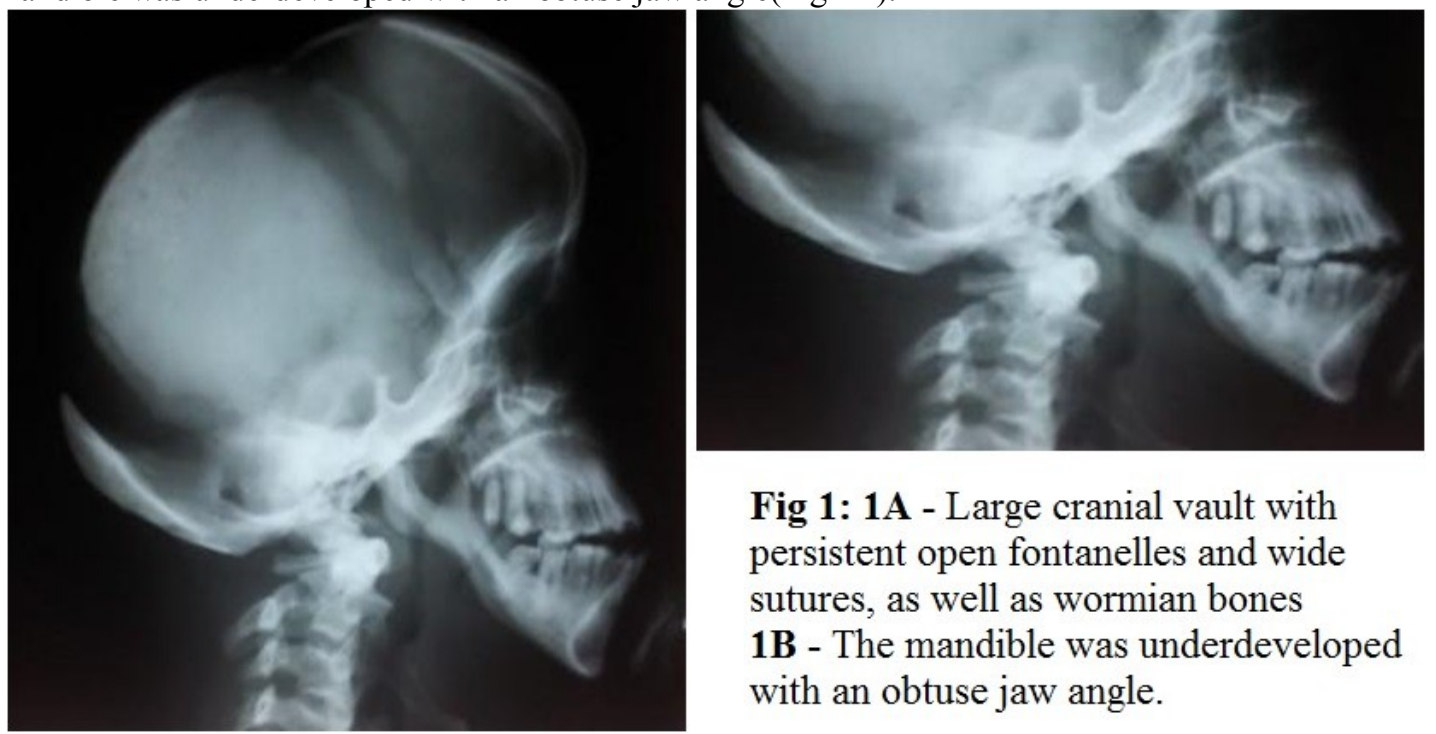

Fig 1: 1A - Large cranial vault with persistent open fontanelles and wide sutures, as well as wormian bones 1B - The mandible was underdeveloped with an obtuse jaw angle. 
The long bones demonstrated clear osteosclerosis, with poorly formed medullary spaces. Evidence of previous fractures of both femurs and tibia that had healed with angular deformities was noted (Fig 2).

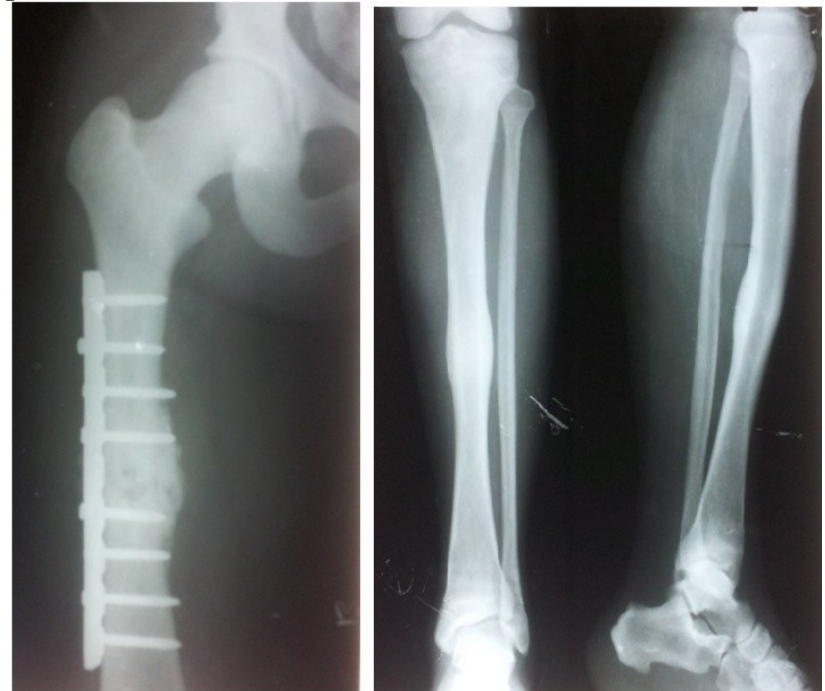

Fig 2 : Long bones demonstrated clear osteosclerosis, with poorly formed medullary spaces and evidence of previous fractures.
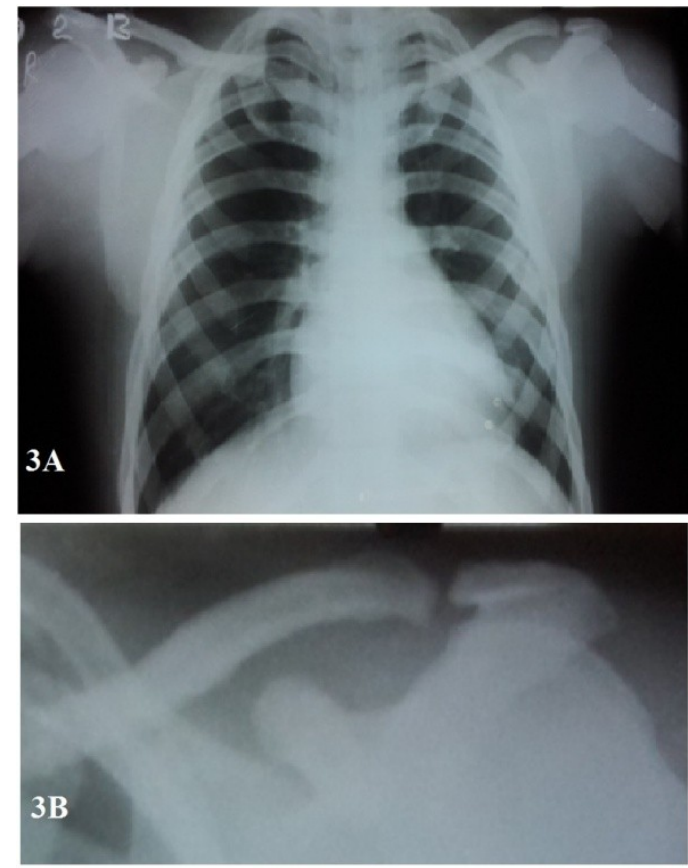

Fig $3: \mathbf{3 A}$ - Chest radiograph $\mathbf{3 B}$ - Clavicular hypoplasia :Underdeveloped acromion with a large acromio-clavicular joint space.

The acromion was underdeveloped, with a large acromio-clavicular joint space - clavicular hypoplasia (Fig 3). Films of the hands showed aplastic terminal phalanges in keeping with acro-osteolysis and abnormal radio-ulnar articulation (Fig 4). These characteristic radiological Features lead to a diagnosis of pycnodysostosis. Similar radiological findings were also noted in other two male siblings of the patient.

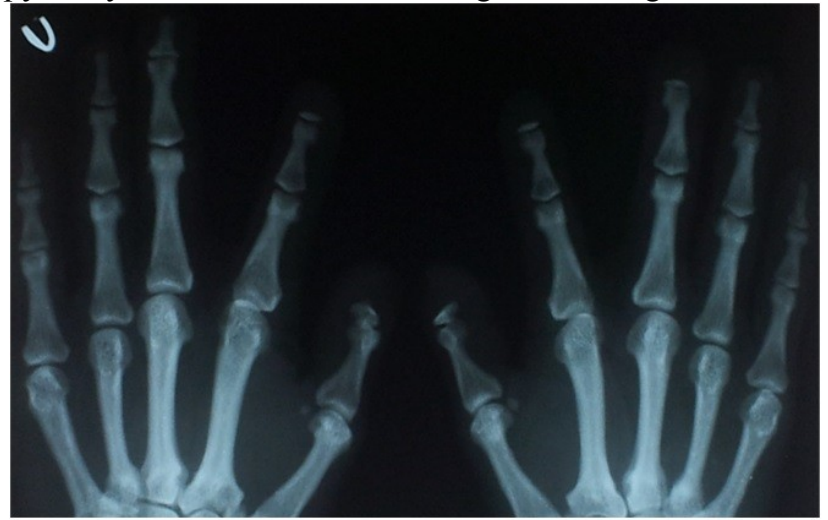

Fig 4: Aplastic terminal phalanges

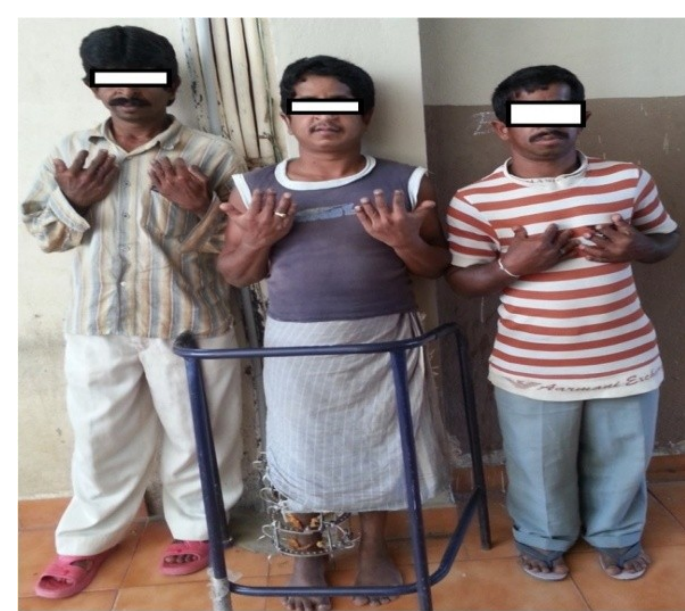

Fig 5 : Clinical Photograph of a family of 3 males with Pycnodysostosis. Dysmorphic features with short stature and proportionately short limbs; Larger head with a small facial structure; short digits of hand.

\section{Discussion :}

Pycnodysostosis is an autosomal recessive disease characterised by systemic osteosclerosis owing to decreased bone turnover ${ }^{3}$. During the 1990s, the genetic defect was located on chromosome 1q21 which led to specific genetic testing and accurate diagnosis ${ }^{5}$. A mutation in the gene that codes for the enzyme cathepsin $\mathrm{K}$ inhibits the normal functioning of osteoclasts ${ }^{6}$. Defective osteoclasts cause impaired bone resorbtion and 
remodelling, which is essential for normal bone maintenance, both during growth and healing ${ }^{7}$. Bones in affected individuals are therefore abnormally dense and brittle and easily fracture ${ }^{8}$.

The disorder is normally diagnosed at a young age owing to the characteristic phenotypical appearance with proportionate dwarfism and dysmorphic facies ${ }^{9,10}$. It is, however (as in our case), sometimes diagnosed late, as a result of inclination to fractures and infections resulting from increased bone density and impaired bone vascularity. Cognitive functioning and life expectancy for pycnodysostosis sufferers is normal.

Several bone diseases should be considered in the differential diagnosis of pycnodysostosis, most importantly cleidocranial dysostosis, osteogenesis imperfecta and osteopetrosis ${ }^{11}$. Cleidocranial dysostosis presents similarly to pycnodysostosis, with persistent open fontanelles and cranial sutures; however, it always involves the clavicle more often than Pycnodysostosis and does not result in overall increased bone density.

Osteopetrosis also causes generalised osteosclerosis and increased bone density; however, the medullary cavities in the long bones are obliterated, and patients present with anaemia ${ }^{12}$. Increased density of the skull base causes attenuation of foraminae, with resultant compression symptoms of the cranial nerves. Renal osteodystrophy causes pathological fractures with sclerosis. The diagnosis is primarily based on the afore mentioned radiographic features. However, a cathepsin $\mathrm{K}$ gene mutation analysis remains the gold standard confirmatory test. No specific treatment options exist, so treatment is supportive, with fracture prevention and management constituting the most important aspects of clinical care. Dental hygiene and regular checkups are also helpful in preventing complications ${ }^{13}$.

\section{Conclusion:}

Pycnodysostosis is a rare condition that is diagnosed primarily on its radiographic features and history of multiple fractures of shaft of long bones with trivial trauma. The importance of recognition of these features in the diagnosis and prevention of future complications is stressed in this case report.

\section{References :}

[1]. Yeo TC. Pycnodysostosis--report of a case. Singapore Med J; 1988;29:611-616

[2]. Elmore SM: Pycnodysostosis: a review. J Bone Joint Surg [Am] 1967, 49:153-161.

[3]. Elmore SM, Nance WE, McGee BJ, et al. Pycnodysostosis with a familial chromosome anomaly. Am J Med 1966;40:273-82.

[4]. Helms CA. Metabolic bone disease. In: Brant WE, Helms CA, eds. Fundamentals of Diagnostic Radiology. Philadelphia: Lippincott Williams \& Wilkins 1999:1049-1059.

[5]. Forland M. Cleidocranial dysostosis. A review of the syndrome and report of a sporadic case, with herediatary transmission. Am $J$ Med 1962;33:792-799.

[6]. Motyckova G, Fisher DE: Pycnodysostosis: Role and Regulation of Cathepsin K in Osteoclast Function and Human Disease. Curr Mol Med 2002, 2:407-421.

[7]. B Bernard, W Hiddema; Pycnodysostosis with the focus on clinical and radiographic findings; S Afr J Rad 2012;16(2):74-76.

[8]. Mujawar Q, Naganoor R, Patil H, Thobbi AN, Ukkali S, Malagi N. Pycnodysostosis with unusual findings: a case report. Cases Journal 2009;2:6544.

[9]. Hernandez-Alfaro F, Arenaz-Bua J, Serra Serrat M, Mareque Bueno J. Orthognathic surgery in pycnodysostosis: a case report. Int J Oral Maxillofac Surg 2011;40:106-123.

[10]. H Kamak, G Kamak, I Yavuz; Clinical, radiographic, diagnostic and cephalometric features of pycnodysostosis in comparison with Turkish cephalometric norms: A case report ; European journal of Dentistry ; October 2012 - Vol.6; 454-459.

[11]. Wolpowitz A, Matisonn A. A comparative study of pycnodysostosis, cleidocranial dysostosis, osteopetrosis and acroosteolysis. $S$ Afr Med J 1974;48:1011-1018.

[12]. Beighton P, Horan F, Hamersma H. A review of the osteopetroses. Postgrad Med J 1977;53:507-516.

[13]. Soliman AT, Ramadan MA, Sherif A, Aziz Bedair ES, Rizk MM. Pycnodysostosis: clinical, radiologic, and endocrine evaluation and linear growth after growth hormone therapy. Metabolism 2001;50:905-911. 